\title{
O ENSINO DO DIREITO PENAL NOS CURSOS JURÍDICOS: Necessidade de uma Formação Humanística e Consciência Crítica Responsável
}

http://dx.doi.org/10.21527/2176-6622.2020.53.247-258

Recebido em: 21/11/2018

Aceito em: 28/12/2019

Sonia Do Carmo Groberio

Doutoranda em Direitos e Garantias Constitucionais pela Faculdade de Direito de Vitória/ES. Mestre em Direitos e Garantias Fundamentais Constitucionais pela Faculdade de Direito de Vitória/ES (FDV). http:// lattes.cnpq.br/7068629984990225. http://orcid.org/000.0003-3819-6814. sonia.groberio@gmail.com

\section{Gilsilene Passon Francischetto}

Pós-doutora pelo Centro de Estudos Sociais de Coimbra. Doutora em Direito e Economia pela Universidade Gama Filho. Mestre em Instituições Jurídico-políticas pela UFSC. Professora e pesquisadora do Programa de Pós-Graduação Stricto Sensu - Mestrado e Doutorado - em Direitos e Garantias Fundamentais da FDV. Coordenadora do grupo de pesquisa da FDV "Invisibiidade social e Energias Emancipatórias em Direitos Humanos". http://lattes.cnpq.br/3383944246681351. http://orcid.org/000-0002-8437-8160. Email: gilsilenepasson@uol.com.br

\section{RESUMO}

Trata da análise da educação jurídica e da reflexão sobre seu distanciamento da realidade brasileira e mostra como a disciplina de Direito Penal poderá contribuir para uma formação humanística, com uma consciência crítica responsável, capaz de avançar para além do dogmatismo e da zona de conforto do penalismo técnico-jurídico e criar novos caminhos para a efetivação dos direitos. Os egressos dos cursos de Direito, em sua maioria, replicam na prática os seus estudos, com mera reafirmação da lei, reproduzindo um conhecimento descontextualizado, dogmático e unidisciplinar. Utiliza-se o método hipotético-dedutivo. O levantamento e a análise do material bibliográfico foram desenvolvidos com o intuito de fundamentar os conhecimentos já consolidados sobre o assunto, bem como apresentar os pontos controversos sobre a temática. Conclui-se que deve ser aplicada à disciplina de Direito Penal a Criminologia, incluindo a Criminologia Crítica, que possui caráter decisivo com relação à forma de aplicação e interpretação do controle jurídico penal, e a Política Criminal, de forma conjugada, colocando em prática a previsão das Diretrizes Curriculares Nacionais atuais para os cursos de Direito (Resolução no 9/2004), do Conselho Nacional de Educação (CNE).

Palavras-chave: Educação jurídica. Criminologia crítica. Formação humanística.

THE TEACHING OF CRIMINAL LAW IN LEGAL COURSES:

THE NEED FOR HUMANIST TRAINING AND RESPONSIBLE CRITICAL CONSCIOUSNES

\section{ABSTRACT}

It deals with the analysis of legal education and reflection on its distancing from the Brazilian reality and shows how the discipline of criminal law can contribute to a humanistic formation with a responsible critical conscience, capable of moving beyond dogmatism and the comfort zone of penalism technical and legal and create new paths for the realization of rights. The graduates of Law courses, for the most part, replicate in practice their studies, with a mere reaffirmation of the law, reproducing a decontextualized, dogmatic and unidisciplinary knowledge. The hypothetical-deductive method is used. The collection and analysis of the bibliographic material was developed with the purpose of substantiating the knowledge already consolidated on the subject, as well as presenting the controversial points on the subject. It concludes that it is necessary to apply to the disciplines of Criminal Law, Criminology, including Critical Criminology, which is decisive in relation to the form of application and interpretation of criminal legal control and Criminal Policy, in a conjugated way, putting in practice the prediction of the current National Curricular Guidelines for Law courses (Resolution no. 9/2004), of the National Education Council (CNE).

Keywords: Legal education. Critical criminology. Humanistic training.

\section{SUMÁRIO}

1 Introdução. 2 A educação jurídica no brasil: da criação dos cursos às inovações na legislação. 3 A educação jurídica e a formação humanística. 4 Ensino da disciplina de Direito Penal integrado com a Criminologia Crítica e Política Criminal visando à formação de uma consciência crítica responsável. 5 Considerações finais. 6 Referências. 


\section{INTRODUÇÃO}

Uma das principais críticas em relação à educação jurídica sempre foi o seu distanciamento da realidade social, o que vem alertando para a crise da referida educação no Brasil. Essa crise, segundo Linhares (2010, p. 239), também não é recente e remonta historicamente à própria criação dos dois cursos jurídicos, um em São Paulo, no Estado de São Paulo, e outro em Olinda, Pernambuco. Em virtude dessas críticas surgiram as reformas da educação jurídica principalmente relacionadas às mudanças na legislação educacional.

Registra-se, nesse sentido, as normas sobre a organização dos cursos jurídicos brasileiros, como a revogada Portaria no 1.886/94, do Ministério da Educação (MEC), e as Diretrizes Curriculares Nacionais atuais para os cursos de Direito (Resolução no 9/2004), do Conselho Nacional de Educação (CNE). Ou seja, conforme destaca Linhares (2010, p. 244), transcorridos mais de 180 anos de criação dos cursos jurídicos no Brasil, discutem-se, ainda nos dias atuais, além das recentes mudanças ocorridas em 2017, mais reformas no ensino e no currículo jurídico.

Apesar das mudanças na legislação, no entanto, a educação jurídica não tem conseguido acompanhar as transformações sociais, políticas e econômicas pelas quais o país tem passado, mostrando que a reforma não pode se restringir à elaboração de alteração na matriz curricular. É necessário também uma mudança de comportamento e postura dos agentes envolvidos no processo educacional, principalmente na aplicabilidade do Direito Penal. O ensino do Direito Penal ainda é aplicado de forma excessivamente legalista e formalista, sem instrumentos de compreensão da realidade dinâmica da sociedade, o que vem aumentando a distância entre essa realidade e os bancos escolares.

Busca-se no presente artigo tratar do distanciamento entre a educação jurídica e a realidade da sociedade brasileira e mostrar que a disciplina de Direito Penal deve ser aplicada de forma integrada com a criminologia, incluindo a Criminologia Crítica e a Política Criminal, tendo como embasamento teórico o pensamento do filósofo, sociólogo e jurista italiano Alessandro Baratta.

O ensino da Criminologia Crítica possui caráter decisivo com relação à forma de aplicação e interpretação do controle jurídico penal, o que poderá contribuir para uma formação humanística, com uma consciência crítica responsável, capaz de avançar para além do dogmatismo e da zona de conforto do penalismo técnico-jurídico e criar novos caminhos para a efetivação dos direitos.

O levantamento e a análise do material bibliográfico foram desenvolvidos com o intuito de fundamentar os conhecimentos já consolidados sobre o assunto, bem como apresentar os pontos controversos sobre a temática, fomentando a discussão para uma possível mudança na dinâmica da Educação Jurídica.

\section{A EDUCAÇÃO JURÍDICA ${ }^{1}$ NO BRASIL: DA CRIAÇÃO DOS CURSOS ÀS INOVAÇÕES NA LEGISLAÇÃO}

Muitos brasileiros à época do Brasil Império estudavam na Universidade de Coimbra, em Portugal, e com a Revolução do Porto houve a suspensão das aulas naquela Universidade, o que fez com que eles retornassem ao Brasil. Nesse período a educação de nível superior era um privilégio das classes sociais dominantes no Brasil e o curso de Direito foi, por muito tempo, a principal opção para a formação da burocracia estatal, segundo Carvalho (2002, p. 10).

Após a Independência brasileira, o Visconde de São Leopoldo apresentou na Assembleia o projeto de criação dos cursos jurídicos no Brasil. Assim, a instalação destes cursos e a definição dos seus Estatutos foram temas discutidos entre 1823 e 1827. A instalação dos dois primeiros cursos de Direito no Brasil ocorreu em 1827, um em São Paulo e outro em Olinda, este posteriormente transferido para Recife em 1854. A escolha pela regionalização dos cursos se justificava para funcionar como um elo entre o Norte e o Sul do país e os locais onde funcionavam os cursos ainda não eram nominados de Faculdades e sim Academias de Direito.

\footnotetext{
Utiliza-se a expressão Educação Jurídica por ser mais abrangente que o Ensino Jurídico, como esclarece Eduardo C. B. Bittar (2001, p. 1516), que por meio da educação se envolvem todos os processos culturais, sociais, éticos, familiares, religiosos, ideológicos, políticos. que somam para a formação e o desenvolvimento do Ensino Jurídico e das potencialidades humanas. Tais potencialidades podem ser psíquicas, físicas, morais, intelectuais, por quaisquer meios possíveis e disponíveis, extraídos ou não do convívio social, enquanto o ensino é um capítulo da educação de uma pessoa.
} 
Acrescenta Francischetto (2010, p. 12) que a característica marcante das Faculdades de Olinda e São Paulo era a semelhança em termos curriculares, metodológicos e filosóficos com os Estatutos da Universidade de Coimbra.

Entre 1828 e 1870, segundo Carvalho (1980, p. 11), os cursos de Direito forneceram os quadros burocráticos e políticos do Império, como ressalta também Linhares (2010, p. 241):

Tais cursos jurídicos prestaram-se, então, a um papel político fundamental: formaram os jovens, filhos da elite, que ocupariam os cargos públicos do nascente Estado Brasileiro e seriam os responsáveis ideológicos pela sua consolidação, já que conferir um diploma de graduado em Direito significava a certeza de ótima colocação social.

Verifica-se que a criação desses cursos refletiu a exigência de uma elite sucessora da dominação colonial que buscava concretizar a independência político-cultural, recompondo ideologicamente a estrutura de poder e preparando uma nova camada burocrático-administrativa.

Nesse sentido, Wolkmer (2000, p. 25) salienta que o surgimento dos cursos de Direito tinha como objetivo atender aos interesses do Estado e não resolver os problemas jurídicos da sociedade e os bacharéis de Direito formados pelas faculdades brasileiras repetiam a doutrina liberal europeia. Assim, no Brasil, a homogeneidade foi garantida pela socialização, treinamento e carreira, o que se pode denominar de homogeneidade ideológica, mesmo quando não havia homogeneidade social.

Quanto à educação como papel de homogeneização da elite, Carvalho $(1980$, p. 12) ressalta a importância do Ensino Superior, que acabou por formar "[...] uma ilha de letrados num mar de analfabetos". Observa-se que, com a formação voltada para questões ideológicas, o conteúdo sobre formação humanística e os direitos dos cidadãos foram deixados de lado.

Sob a alegação de que a educação jurídica estava em crise, foram promovidas várias mudanças na estrutura curricular dos cursos jurídicos durante o Império e a República, na busca por melhorias. Conforme registra Linhares (2010, p. 344), entretanto,

as inovações mais marcantes só ocorreram em 1994 com a participação das comissões de ensino jurídico do MEC e da OAB, além de diversos professores das instituições de ensino superior do Brasil. Dentre as mudanças destaca-se a inclusão do ensino, pesquisa e extensão, as matérias de formação básica, a previsão da interdisciplinaridade, o estágio nos núcleos de prática jurídica e o trabalho de conclusão de curso.

Embora exista o reconhecimento da importância das mudanças, a Educação Jurídica ainda possui uma visão formalista, acrítica e com tendências pedagógicas já ultrapassadas. Essas características do ensino levam ao entendimento de que o jurista precisa apenas conhecer as normas sem qualquer valoração, levando à formação de profissionais com perfil técnico, sem referências na realidade social, desconsiderando o trato devido ao ser humano. Ou seja, limitam-se aos preceitos legais e ao formalismo processual sem preocupação com a função social da atividade, o que é facilmente identificado no ensino e posteriormente, na prática do Direito Penal.

Destacam Prando e Santos (2016 , p. 1) que desde a reforma de 1994, a disciplina de Criminologia é aplicada antes do estudo do Direito Penal. Como enfatizam os autores,

a pretensão, do ponto de vista de uma formação dogmático-jurídica, é a utilidade prática desta disciplina, bem como das demais matérias propedêuticas. De modo usual, entretanto, o que se aprende nos primeiros anos do curso de Direito permanece como produto de perfumaria, para então, nos anos seguintes, se firmar o estudo do Direito exclusivamente com disciplinas técnico-jurídicas. Desde a faculdade, portanto, o operador jurídico não consegue perceber a relação estrutural entre teoria e prática. Essa formação acadêmica está intrinsecamente relacionada ao paradigma jurídico preponderante, que se funda sob os pressupostos liberais e positivistas, nos quais os conflitos sociais e as relações entre as várias esferas de poder não são compreendidos como parte constitutiva do universo do Direito.

Verifica-se nas várias profissões que exigem a formação jurídica como requisito para o ingresso, o reflexo do ensino do Direito Penal nas diversas faculdades por meio da repetição mecânica da previsão legal em suas decisões, sem considerar o contexto social. Como nos traz Pedroto (2018, p. 77), ao tratar da aplicabili- 
dade da Lei de Drogas por parte dos delegados de Polícia Civil do Estado do Espírito Santo, ressaltando que a formação desses profissionais acaba sendo muito voltada à aplicação pura da lei, sem maiores considerações a respeito das repercussões socioculturais envolvendo as drogas, lícitas ou ilícitas, por exemplo.

Os desafios e o papel da Educação Jurídica na sociedade contemporânea são evidentes. Existem, no entanto, inúmeras críticas, pois o referido ensino vem sendo pautado em três perspectivas, que são a descontextualização, o dogmatismo e a unidisciplinaridade, como nos ensina Francischetto (2010, p. 11). Quando se fala em descontextualização do Direito, as críticas referem-se à aceitação do ordenamento jurídico como única fonte de produção de normas, desconsiderando o pluralismo jurídico, que trata do reconhecimento do Direito do Estado como fonte central das leis, mas considera também a produção de normas de conduta oriundas do meio social, bem como a interação dessas normas com a legislação vigente.

Conforme Linhares (2010, p. 30), após o golpe militar de 1964, acentua-se a tendência de profissionalização dos cursos de Direito, entretanto as faculdades transmitem aos alunos informações genéricas e presas à legislação, produzindo um conhecimento desarticulado da sociedade e pouco sistematizado, incapaz de oferecer respostas satisfatórias para a compreensão do ambiente e de preparar profissionalmente o bacharel. Nesse sentido, De Giorgi (2006, p. 251), argumenta que

o curso jurídico fornece referências conceituais que têm a função de observar quanto a produção jurídica distancia-se e se aproxima dos limites que essas referências conceituais delineiam. Em razão disso, o saber que pode ser produzido nas Universidades oscila entre esquemas universalísticos de princípios desprovidos de fundamento e os particularismos de suas fragmantações impostas pela contingência.

No ensino dogmático existe apenas a reprodução do conhecimento, sem que seja elaborado nenhum questionamento ao que é exposto. Dessa forma, as leis são tidas como algo pronto e acabado que não deve ser contestado, mas apenas interpretado e aplicado. E quanto à unidisciplinaridade, a crítica é em relação à fragmentação do conhecimento jurídico, pois sendo considerada uma ciência autônoma, as Ciências Jurídicas não se comunicam com outras áreas do conhecimento. Assim, o Direito é exposto por meio de disciplinas, transmitindo a ideia de que é possível compreender uma delas sem que haja uma ligação com as demais, não se praticando a transdisciplinaridade.

Para promover a transdisciplinaridade, segundo Morin (2000, p. 40), é necessária a adoção de um paradigma que permita distinguir, separar, opor e disjuntar os domínios científicos, fazendo com que eles se comuniquem entre si, porém sem reduzi-los, ou seja, um paradigma de complexidade que disjunte e associe ao mesmo tempo diante das emergências da realidade. A transdisciplinaridade é a passagem do simples ao complexo e comporta a interdisciplinaridade e a transversalidade, sem as quais não consegue realizar-se complexamente. Essa realização exige uma contextualização global dos conhecimentos, conforme explica Edgar Morin (2000, p. 13):

A atitude de contextualizar e globalizar é uma qualidade fundamental do espírito humano que o ensino parcelado atrofia e que, ao contrário disso, deve ser sempre desenvolvida. O conhecimento pertinente é aquele que é capaz de situar toda a informação em seu contexto e, se possível, no conjunto global no qual se insere.

O currículo da Educação Jurídica adota uma concepção legalista do Direito, ou seja, na qual as leis devem ser interpretadas de modo racional e positivista, cujas características têm presença marcante no ensino das disciplinas de Direito Penal que ocupa um lugar central e espaçoso nos currículos dos cursos de Graduação e Pós-Graduação em Direito.

Os operadores do Direito egressos das universidades, contudo, devem estar aptos a participar do desenvolvimento da sociedade colaborando com a efetivação da cidadania. Isso somente será possível a partir de um conhecimento transversal da ciência jurídica que traga uma prática libertadora para a sociedade. $O$ ensino das ciências jurídicas clama por um discurso nos cursos de Direito que seja complexo, interdisciplinar e transversal para a construção de um currículo completo e emancipatório, que permitirá ao aluno o livre exercício de sua cidadania e a competência de ser um operador do Direito realmente preocupado com a sociedade de uma forma ética e humanitária. 
Algumas das soluções apontadas já estão previstas nas Diretrizes Curriculares Nacionais, Resolução no 9, de 29 de setembro de 2004, bem como a inclusão da necessidade de uma sólida formação humanística na Educação Jurídica, mas na prática a incorporação dessas inovações ainda é limitada, como será tratado na sequência.

\section{A EDUCAÇÃO JURÍDICA E A FORMAÇÃO HUMANÍSTICA}

As Diretrizes Curriculares atuais para os cursos de Graduação em Direito que foram instituídas pela Resolução CNE/CES no 9/2004, repetiram o conteúdo da Portaria 1.886/94 e acrescentaram no artigo 3ㅇ a preocupação com uma formação humanística no ensino jurídico. Dessa forma, o referido artigo traz entre outras indicações que:

Art. 3-- [...] sólida formação geral, humanística e axiológica, capacidade de análise, domínio dos conceitos e da terminologia jurídica, adequada argumentação, interpretação e valorização dos fenômenos jurídicos e sociais, aliada a uma postura reflexiva e de visão crítica que fomente a capacidade e aptidão para a aprendizagem autônoma e dinâmica, indispensável ao exercício da ciência do Direito, da prestação da Justiça e do desenvolvimento da cidadania (LINHARES, 2010, p. 350).

No entendimento de Linhares (2010, p. 350), pelo previsto no referido dispositivo, um dos objetivos é proporcionar a formação humanística do aluno, ou seja,

não deve um curso de Direito se preocupar com um currículo exclusivamente voltado para uma formação técnico-jurídica. É preciso oferecer ao aluno a possibilidade de uma formação de cultura geral, que o prepare para a vida, para o desenvolvimento integral de suas capacidades e potencialidades como ser humano, no sentido de uma educação holística e não somente voltada para uma profissão.

Diante do objetivo de proporcionar a formação humanística ao aluno, surge a questão de como se daria essa formação. Defende-se que se deve trabalhar com interdisciplinaridade e transversalidade, incluindo disciplinas como Direitos Humanos e Ética, porém no atual contexto social constata-se que isso não basta. Deve-se, sim, utilizar a transversalidade e aliar também a teoria à prática.

Além da previsão do Artigo 3, foram incluídas nas Diretrizes Curriculares do curso de Direito as disciplinas: Ética; Filosofia; História; Psicologia e Sociologia. A inclusão dessas disciplinas foi uma tentativa de tornarem seus conteúdos obrigatórios, pois são essenciais para a formação do ser humano, podendo proporcionar uma visão mais humana e social aos acadêmicos de Direito, além da necessidade constante da reflexão sobre temas como justiça e igualdade social.

Apesar da inclusão dessas disciplinas, no entanto, não ocorreram avanços significativos na Educação Jurídica, o que pode ser atribuído, entre outros fatores, à expansão indiscriminada e sem critérios de cursos de Direito no Brasil. Registra-se, segundo dados no e-MEC, ${ }^{2}$ que em 2018 foram contabilizados um total de 1.259 cursos de Direito em funcionamento, com a possibilidade de preenchimento de 200 mil vagas por ano. ${ }^{3}$

Acrescenta-se a falta de qualificação dos docentes e o modelo de ensino adotado no Brasil, que é técnico e dogmático, voltado para a aprovação na $O A B$ e em outros concursos jurídicos. O Exame da Ordem também segue a mesma linha, como ressalta Francischetto (2010, p.156), pois os candidatos não são avaliados no tocante à formação ética e é exigido somente o conhecimento relacionado às regras de deontologia jurídica constante na legislação pertinente.

É necessário o empenho de todos os envolvidos, como ilustra Paulo Freire (1996, p. 54): "minha presença no mundo não é de quem a ele se adapta, mas a de quem nele se insere. É a posição de quem luta para não ser apenas objeto, mas sujeito também da história". Por isso, o desafio de aproximar o ensino do Direito da realidade deve considerar a participação dos docentes e as expectativas e os perfis diferenciados dos es-

\footnotetext{
Sistema eletrônico de acompanhamento dos processos que regulam a educação superior no Brasil.

3 Esse número crescente de cursos de Direito demonstra a fragilidade do sistema de regulação do Ensino Superior nessa área. Dados do e-MEC, disponível em: http://emec.mec.gov.br/. Acesso em: 25 ago. 2018.
} 
tudantes, que devem estar cientes de que o ensino e o aprendizado do Direito não se esgotam na leitura de manuais e em aulas expositivas e possam ser protagonistas de um aprendizado que conecte o Direito com sua própria realidade.

O ensino nos cursos jurídicos ainda leva em consideração o modelo estipulado pelo positivismo jurídico e dessa forma acaba servindo como instrumento das ideologias estatais, seguindo a mesma filosofia dos cursos jurídicos iniciais no Brasil, distanciando-se das reais necessidades sociais. É necessário superar esse paradigma de modo que tanto os docentes quanto os discentes entendam a relevância de se promover uma Educação Jurídica criativa, crítica, sem ignorar a realidade social e trabalhando os temas técnicos ligados ao fenômeno social que os circunda para uma formação de profissionais críticos e sensíveis às necessidades sociais.

Uma das mudanças necessárias nos cursos juridicos é a inclusão do estudo da Criminologia incluindo a Criminologia Crítica ${ }^{4}$ e o ensino do Direito Penal e da política criminal de forma integrada, como será apresentado no próximo tópico .

\section{ENSINO DA DISCIPLINA DE DIREITO PENAL INTEGRADO COM A CRIMINOLOGIA CRÍTICA E POLÍTICA CRIMINAL VISANDO À FORMAÇÃO DE UMA CONSCIÊNCIA CRÍTICA RESPONSÁVEL}

O Direito Penal está relacionado culturalmente à punição, pois no senso comum penal é igual à "pena"ou "suplício". ${ }^{5}$ O Direito Penal, entretanto, tem como um dos objetivos a proteção ou a garantia dos bens jurídicos que são assegurados pela Constituição. Essa proteção dos direitos é realizada pelo Estado por meio da privação dos bens jurídicos efetivados pelo sistema penal que envolve o poder Judiciário, o Ministério Público, a polícia, o sistema prisional, entre outros.

Assim, o Direito Penal apresenta-se, por um lado, segundo Bitencourt (2012, p. 57), como um conjunto de normas jurídicas que tem por objeto a determinação de infrações de natureza penal e, por outro lado, apresenta-se como um conjunto de valorações e princípios que orientam a própria aplicação e interpetação das normas penais, cuja finalidade é tornar possível a convivência humana, observando-se os princípíos de justiça.

Observa-se, no entanto, que a prática penal ocorre de maneira diversa, como ressaltam Prando e Santos (2016, p. 10), principalmente pela atuação voltada para o controle e repressão ao crime. Esse controle, para os referidos autores, é

feito quase que exclusivamente através da segregação dos apenados (as novas penas não são propriamente "alternativas", mas complementares à segregação), não garante a efetivação e a proteção dos direitos fundamentais. A repressão é definida, inclusive, pelo caráter desigual de sua aplicação. Assim, aqueles alcançados pelo sistema penal, além de não se constituírem pela maioria dos que efetivamente cometem delitos, são "selecionados", isto é, verdadeiramente escolhidos: não pela sua conduta, mas pelo seu status social.

Ressalta-se que para a aplicabilidade prática do Direito Penal tem-se ainda outros desafios que são as mudanças sociais atuais, cuja sociedade é caracterizada como "sociedade de risco", expressão utilizada por vários autores, como Niklas Luhmann (2006); Rafaelle De Giorgi (2009); Boaventura Sousa Santos (2002); Ulrich Beck (2010), entre outros.

Em relação a essas mudanças, como traz De Giorgi (2006, p. 235), "Surgem novas figuras dogmáticas que impõem, aos atores particulares do Direito, controle do risco ou que sancionam comportamentos lícitos se, em virtude do exercício do Direito, são produzidos danos que se queriam evitar".

\footnotetext{
${ }^{4}$ Criminologia Crítica é uma teoria criminológica de inspiração marxista concebida por Alessandro Baratta, com base epistemológica na teoria do etiquetamento do sistema penal, isto é, na seletividade dos órgãos de controle social formal (do Estado), como pobres, negros, egressos e outras minorias análogas. Ver: (ANDRADE, 2017) Disponível em: htpp//www.portaldeperiodicos.unisul.br/index.php/. Acesso em: ago. 2018.

5 É o pensamento ainda reinante na sociedade, embora de acordo com a legislação penal brasileira "a pena deve reprovar o mal produzido pela conduta praticada pelo agente, bem como prevenir futuras infrações penais". Ver: GRECCO, Rogério. Código Penal Comentado (2011).
} 
A partir dessas modificações na sociedade, verifica-se que são especialmente relevantes para o desenvolvimento da criminalidade e do Direito Penal, como destaca Sibier (2008, p. 271), duas linhas centrais que se fortalecem mutuamente, ou seja:

- O processo de "globalização" proporciona novas oportunidades de execução de crimes que ultrapassam fronteiras, levando o Direito Penal aos seus "limites territoriais" e exigindo novos modelos de um Direito transnacional eficaz.

- O desenvolvimento da "sociedade de informação e da sociedade de risco" gera novos riscos e uma criminalidade complexa, que também leva o Direito Penal - principalmente no contexto de uma crescente política criminal global - a seus "limites funcionais" na proteção da sociedade e da liberdade do indivíduo e o coloca ante novos desafios categoriais.

Essas duas linhas centrais apresentadas mostram a necessidade de atualização constante dos conteúdos das disciplinas integrantes da matriz curricular dos cursos de Direito, principalmente a disciplina de Direito Penal, que deve caminhar lado a lado com as modificações na sociedade com uma prática contextualizada.

Quanto à Criminologia, é uma disciplina que por estar vinculada à Sociologia Penal, está mais capacitada para perceber a importância do conhecimento negado pelo estudo dogmático dos crimes e das penas, atentando para os problemas decorrentes da sua realização na sociedade. Como as demais disciplinas propedêuticas existentes nos currículos dos cursos de Direito, a Criminologia tem como objetivo geral vincular a compreensão do sistema penal às influências das esferas política, econômica, cultural e social. Para Prando e Santos (2016 , p. 3), seu objetivo específico é "mensurar, analisar e refletir sobre as práticas repressivas, institucionalizadas ou não, e seus respectivos discursos de justificação".

A Criminologia Crítica ganhou projeção no final dos anos 60 e no início dos anos 70, aproveitando a oportunidade aberta pelos movimentos de reivindicação de direitos civis. A função primordial dessa disciplina é denunciar a seletividade do sistema penal, desmistificando-o, especialmente em relação à premissa de que pune todos igualmente, por excelência, e de que o funcionamento do Direito Penal é exemplar, como ressalta Baratta (1999, p. 160-161):

O salto qualitativo que separa a nova da velha Criminologia consiste, portanto, principalmente, na superação do paradigma etiológico, que era o paradigma fundamental de uma ciência entendida, naturalisticamente, como teoria das causas da criminalidade. A superação deste paradigma comporta, também, a superação de suas implicações ideológicas: a concepção do desvio e da criminalidade como realidade ontológica preexistente à reação social e institucional e a aceitação acrítica das definições legais como princípio de individualização daquela pretendida realidade ontológica - duas atitudes, além de tudo, contraditórias entre si.

Nesse sentido, os debates em torno da Criminologia Crítica e sobre a Política Criminal concentraram-se na mudança do núcleo de abordagem, ou seja, da norma material, da conduta prevista no Código Penal e não nas estratégias político-criminais sobre a proporcionalidade das penas ou a necessidade de inclusão de um novo tipo penal. Para Ferreira (2015, p. 143), "a Criminologia anda em círculos: ficou "presa" ao debate sobre a seletividade do sistema de justiça criminal e ao método empírico associado às Ciências Sociais e não formulou qualquer proposta sob a forma de intervenção social, formulação de política pública"

Segundo Baratta (1981, p. 35-36), a preocupação da Criminologia Crítica estava voltada mais para a análise dos sistemas jurídico-penais vigentes do que diretamente para as questões criminológicas que surgiam. Assim, a Criminologia contemporânea tenderia a "transformar-se de uma teoria da criminalidade em uma teoria crítica e sociológica do sistema penal" em virtude da inoperância e falta de argumentos contrários ao recrudescimento crecente, nos sistemas penais.

Igualmente observa Baratta (1999, p. 175) que a Justiça Penal somente administra a criminalidade, não dispondo de meios de combatê-la, funcionando apenas como selecionadora de sua clientela habitual nas classes trabalhadoras. O crime é um subproduto final do processo de criação e aplicação das leis, orientadas ideologicamente às classes dominantes. Percebe-se a negação do Direito Penal como igualdade, em que a lei protege todos. Ressalta-se que para De Giorgi (2006, p. 133), o Direito Penal 
por meio de uma intervenção preventiva, segrega, na exclusão, aquele excedente que, na percepção do futuro por parte da política, constituiria um risco para a produção de exclusão deste normal funcionamento. 0 Direito Penal contribui, assim, para a estabilização de um metacódigo, de uma metadistinção que atravessa os sistemas sociais diferenciados. Trata-se do metacódigo inclusão/exclusão, que ativa a barbárie tipicamente moderna da sociedade mundial.

Para assegurar a sobrevivência deste domínio central, o Direito Penal é usado pelas parcelas sociais detentoras de poder, que é posteriormente ameaçado por suas próprias contradições (BARATTA, 1999, p. 245). Enquanto as classes detentoras do poder político e econômico se perpetuarem neste núcleo inatingível de dominação, as parcelas da população marginalizadas na hierarquia social terão as maiores chances de serem selecionadas para a população criminosa.

Observa-se que o ensino do Direito Penal segue exatamente essa linha apresentada por Baratta, sendo dogmático e apegado às previsões legais. O sistema penal é a parte do controle social que aparece como punitiva e institucionalizada. Inclui desde a suspeita da existência do crime até a execução da pena e compreende, no significado do sistema penal, as atividades do legislador, do jurista, das agências punitivas, da execução penal e até mesmo do público.

A verificação de técnicas de controle social não punitivas é essencial para o sucesso de uma política criminal voltada para os marginalizados. Tais políticas públicas oferecem um menor custo social ao encararem o problema da criminalidade com técnicas de prevenção ao crime de caráter primário. Segundo Baratta (1999, p. 75),

atuam na raiz do conflito, neutralizando o crime antes de ele ocorrer, a médio e longo prazos. São políticas públicas que fornecem a capacidade para o cidadão se organizar socialmente e assim superar conflitos desviantes. Entretanto, na prática existem poucos trabalhos voltados para a prevenção primária ao crime. O controle real da criminalidade não deveria se limitar à esfera do sistema penal, pois deveria buscar um amparo maior nas políticas públicas sociais.

Um modelo de controle social repressivo, que somente atua de modo superficial, individual e de forma local, não resultará em sucesso. No Estado Democrático de Direito que respeite a cidadania, os direitos humanos e o combate às desigualdades sociais, o controle penal não pode ser realizado de forma abusiva. Isso acarretaria a institucionalização da violência e da arbitrariedade.

Registra-se em Baratta (1999, p. 76) que o Direito Penal tem elevado custo social, por vezes irreversível para a vítima, para o criminoso e para sociedade. Uma política de transformação da realidade do sistema penal deve pautar-se por valores constitucionais e alcançar setores populares, não podendo considerar o Direito Penal como principal objeto. Pelo contrário, o Direito Penal, nesse plano democrático, deveria ser subsidiário.

Raffaele De Giorgi (2006, p.165-166) ${ }^{6}$ refere-se ao dúplice percurso reflexivo iniciado por Baratta ao afirmar que de um lado, ocorre o

resgate do pensamento iluminista e reaquisição dos pressupostos do pensamento liberal do Direito Penal, para repensar as categorias penais, a estrutura da pena e da culpa. De outro lado, requeria um Direito Penal auto-imunizado em relação à política e protegido contra os possíveis desvios, por meio da tutela oriunda dos direitos humanos e da conceitualidade dogmática forjada numa hierarquia racional dos bens jurídicos dignos de tutela que fosse resistente às pressões momentâneas da expansão interpretativa.

Pelo exposto, constata-se-se que o estudo da Criminologia é fundamental para a educação jurídica. Apesar disso, ocupa pouco espaço nos cursos de Direito, observando-se que a Criminologia Positivista ocupa espaços nos currículos com posição obrigatória, mas a Criminologia Crítica, quando é incluida, é como disciplina optativa. Já o Direito Penal, que é aplicado voltado para a dogmática jurídica, ocupa amplo espaço, sendo dividido ao longo de todo o curso. Verifica-se que existe uma relação de interdependência entre o Direito Penal, a Criminologia e a Política Criminal, com uma divisão metodológica entre elas, mas cabendo à Criminologia exercer uma função auxiliar tanto para o Direito Penal como para a Política Criminal.

\footnotetext{
Discurso proferido por Raffaele De Giorgi durante a jornada de estudos em homenagem a Alessandro Baratta, ocorrida em 2005 em Gênova, Itália. Ver: DE GIORGI, Raffaele. Direito, tempo e memória. Quartier Latin, São Paulo: 2006, p. 165-166).
} 
Segundo Andrade (2013, p. 181), a dogmática do Direito Penal, entendida como ciência normativa, terá por objeto as normas penais e por método o técnico-jurídico, de natureza lógico-abstrata, interpretando e sistematizando o Direito Penal positivo para instrumentalizar sua aplicação com segurança jurídica. Ressalta ainda o referido autor que

por outro lado, a criminologia, definida como ciência causal-explicativa, terá por objeto o fenômeno da criminalidade, investigando suas causas segundo o método experimental e subministrando os conhecimentos antropológicos e sociológicos necessários para dar fundamento científico à política criminal a quem caberá transformá-la em opções e estratégias concretas e assimiláveis pelo legislador, na própria criação da lei penal e os poderes públicos, para prevenção e repressão ao crime (p. 182).

Ressalta-se que a Política Criminal é exercida por operadores do Direito, principalmente os que pertencem aos poderes públicos, incluindo o poder Judiciário, Ministério Público, Polícias Estaduais e Federal. A ausência de um ensino integrado, com interdisciplinaridade e transversalidade da Criminologia, incluindo a Criminologia Crítica, do Direito Penal e da Política Criminal, influenciam na prática desses operadores do Direito, tendo como resultado a seletividade, a violência institucional do sistema penal, da prisão e a incapacidade de dar respostas satisfatórias às vítimas e às suas famílias.

Nesse sentido Pedroto (2018, p. 130), ao tratar sobre as políticas de drogas ressalta que pesquisas apontam o alto grau de estigmatização e desconhecimento dos magistrados ao julgar causas relacionadas às drogas, extraindo conclusões similares em relação aos delegados de Polícia, afirmando que

essas duas funções públicas estão dentro de um mesmo nível sociocultural e educacional, cujas formações acadêmicas privilegiam a aplicação cega da lei em detrimento da construção multidisciplinar. Em consequência há uma reprodução de comportamentos que reforçam o encarceramento seletivo de grande parte da população vulnerável.

Essa afirmação revela a necessidade de mudanças na formação acadêmica desses profissionais nas faculdades de Direito ao ser ministrada a disciplina de Direito Penal. Conforme registra Andrade (2013, p. 181), surgiu na década de 60 do século 20 uma mudança do paradigma etiológico para o paradigma da reação social, com a Criminologia Crítica.

Dessa forma, a criminologia passa a não mais ser uma ciência que investiga as causas da criminalidade, mas as condições da criminalização, ou seja, como o sistema penal, mecanismo de controle social formal, constrói a criminalidade e os criminosos em interação com o controle social informal, funcionalmente relacionados às estruturas sociais.

Para Andrade (2013, p. 181) a inclusão do estudo da Criminologia e da Criminologia Crítica integradas ao Direito Penal e à Política Criminal nos cursos jurídicos possibilitará a passagem de uma criminologia comportamental e da violência individual para a criminologia da violência institucional. O referido autor nos ensina ainda que não se pode compreender o crime, a criminalidade e os criminosos sem compreender o controle social e penal que os constrói como tais, o que culmina numa criminologia da violência estrutural. É isso que nos leva à compreensão dos criminosos, não a partir da mecânica do controle, mas funcionalmente relacionadas às estruturas sociais, como o capitalismo, o patriarcado, o racismo, entre outras. ${ }^{7} \mathrm{Tem}$ - se ainda que a Criminologia

não mais se define como uma ciência que investiga as causas da criminalidade, mas as condições da criminalização, ou seja, como o sistema penal, mecanismo de controle social formal (poder Legislativo, leis penais, a polícia, o Ministério Público, o poder Judiciário, a prisão, ciências criminais, sistema de segurança pública, dentre outros), constrói a criminalidade e os criminosos em interação com o sistema de controle social informal (familia, escola, mídia, religião, moral, trabalho, dentre outros), funcionalmente relacionados às estruturas sociais (ANDRADE, 2013, p. 181).

Essa mudança de paradigma desloca e redefine a Criminologia de um saber auxiliar do Direito Penal e interno ao modelo integrado, para um saber crítico e externo sobre ele convertido em objeto criminológico, o que resultou na importante obra de criminologia de Alessandro Baratta intitulada Criminologia crítica e crítica do direito penal:introdução à sociologia jurídico-penal. 
A Criminologia Crítica, para Baratta (1999, p. 158), é uma expressão da consciência crítica, resultante de uma tomada de posição filosófica que almeje o questionamento. O objeto de análise da Criminologia Crítica é o conjunto de relações sociais, compreendendo as estruturas econômicas e jurídico-políticas do controle social. Uma dupla contraposição à Criminologia Positivista se coloca. O referido autor acrescenta que "há o deslocamento do enfoque teórico do criminoso para as condições objetivas, estruturais e funcionais presentes na origem do desvio".

Em segundo plano verifica-se o deslocamento dos estudos das causas do desvio criminal para os mecanismos sociais e institucionais pelos quais é construída a realidade social do desvio e, também, para os mecanismos criadores das definições do desvio e da criminalidade (BARATTA, 1999, p. 160).

Destaca-se a importância de se definir o plano de atuação político-criminal, verificando qual a relação com a Criminologia Crítica e como funciona sua atuação no sistema penal. Por política criminal deve-se entender os princípios que orientam a ação política de combate ao crime. Tal técnica oferece valores ao legislador/ intérprete do Direito, justificando politicamente as escolhas estatais nesse certame.

Pelas teorias da Criminologia Crítica verifica-se que o sistema de justiça criminal não é só instrumental, mas seletivo, simbólico. Os discursos são generalizantes e moralizantes, entretanto a atuação é seletiva, restritiva e discricionária. Quando se enfatiza demais a criminalidade e a necessidade de punição, os políticos, bem como a sociedade, se esquecem de criticar a seletividade do sistema. Nesse sentido,

a Criminologia Crítica está em crise e talvez o maior erro da Criminologia Crítica tenha sido negar a seletividade como um fato social. $O$ ponto é indicar o que se pode fazer para enfrentar esta seletividade - como politics, na definição de estratégias parlamentares que tenham por objetivo defender o aumento de penas para certos crimes - ou policy - com a indicação de problemas que definam uma pauta, e a vontade política para movimentar a agenda dos atores políticos, definir programas, formular ações e desenhos de políticas públicas, implementá-las e avaliá-las (FERREIRA, 2015, p. 150).

Embora seja apontada uma crise na Criminologia Crítica, é necessário que essa disciplina seja incluída na matriz curricular para que o ensino jurídico possa acompanhar os debates, bem como no meio acadêmico e dessa forma possa contribuir para o enfrentamento da seletividade que é apontada como fato social.

Ainda existe o pensamento dominante de que a aplicação das penas é capaz de inibir o cometimento de crimes, de evitar reincidências e educar o apenado, ou seja, que as penas previstas no Código Penal brasileiro são a melhor forma de prevenir a criminalidade. Esse é o pensamento tradicional que ainda é transmitido na disciplina de Direito Penal na maiorias dos cursos jurídicos, o que leva o estudante a uma aceitação e visão conformista com o que lhe é ensinado e posteriormente irá reproduzir na sua prática profissional diária.

A reprodução do Direito Penal ensinado nas faculdades e aplicado no ambiente profissional é permeada também pela preocupação com as questões políticas que envolvem decisões no exercício das profissões jurídicas. Isso leva muitos profissionais, mesmo que tenham pensamento diverso, a continuarem suas práticas conforme aprenderam e conforme o costume dos demais profissionais da mesma área para não haver questionamentos, como argumenta Pedroto $(2018$, p. 63) ao afirmar que "existe, sim, uma preocupação - em menor ou maior grau - por parte dos delegados de Polícia nas autuações que produzem, sempre observando o comportamento da imprensa, dos órgãos dos sitema de justiça criminal, dos pares e das repartições de correição".

É necessário uma mudança nesse entendimento e tratar a disciplina de Direito Penal de forma multidisciplinar, utilizando-se da Criminologia Crítica, conforme já exposto, comunicando-se com outras disciplinas, como a Sociologia e a Antropologia, analisando-se outros aspectos para além da letra da lei, possibilitando uma consciência jurídica crítica responsável. Essa perspectiva teórica também tem como objetivo diminuir os impactos do sistema penal sobre as classes subalternas, o que impede a constituição de sujeitos coletivos dispostos a transformar a sociedade.

Acrescenta-se que a educação jurídica deve acompanhar as novas demandas sociais, buscando uma integração com a comunidade. Nesse contexto, não se torna necessário promover alterações curriculares constantes, pois por meio da adoção de novas posturas é possível promover modificações significativas nos cursos de Direito, utilizando-se, por exemplo, o desenvolvimento da integração entre a pesquisa, a prática e a extensão, já previstas nos currículos dos cursos de Direito. 
Dessa forma, a formação humanística seria proporcionada por meio da interdisciplinaridade e transversalidade, despertando o aprofundamento dos conhecimentos pela pesquisa, integrando espaços pelo contato construtivo da extensão e proporcionando uma aplicação prática dos conhecimentos, principalmente os relacionados ao ensino do Direito Penal nos cursos jurídicos.

Ressalta-se, de acordo com Andrade (2013, p. 183), que o estudo da Criminologia, incluindo a Criminologia Crítica, de forma integrada com o Direito Penal e Política Criminal, tem grande importância para o ensino do Direito, pois permite a formação de uma consciência jurídica crítica responsável, capaz de avançar para além do dogmatismo e da zona de conforto do penalismo técnico-jurídico e criar novos caminhos para o enfrentamento das violências individual, institucional e estrutural, sendo essa uma grande contribuição ao ensino e à formação humanística, profissional-cidadã.

\section{CONSIDERAÇÕES FINAIS}

Muitos elementos visando a uma maior aproximação da educação jurídica com a realidade da sociedade já estão previstos pela própria organização básica do Ensino Superior jurídico no Brasil por meio das Diretrizes Curriculares Nacionais.

Os instrumentos de avaliação de cursos adotados pelo MEC para regular a oferta do ensino de Direito no Brasil incorporaram, em grande parte, as críticas e sugestões que vêm sendo feitas desde os primeiros cursos existentes por todos aqueles que apontaram uma crise da educação jurídica brasileira e a incapacidade das instituições e de nossos operadores jurídicos de apresentarem repostas aos problemas de nossa sociedade.

Percebe-se, entretanto, que as mudanças inclusas nas diretrizes para a educação jurídica não foram ainda colocadas em prática e nem aproveitadas de forma suficiente pelas instituições de ensino. É preciso que as instituições mudem o currículo elaborado de forma fragmentada, com perspectivas dogmática, unidisciplinar e descontextualizada.

A educação jurídica clama pela efetivação das diretrizes curriculares que trouxeram uma nova configuração, fundamentada e voltada para uma formação humanística, preocupada com a efetiva construção da cidadania e com o desenvolvimento da sociedade, ultrapassando o pensamento tradicionalista fundado no positivismo e literalmente dogmatizado, para conseguir, desse modo, concretizar a aplicação plena da Justiça.

Os profissionais do Direito, cuja missão maior é proteger e defender a própria liberdade de cada um dos membros da sociedade, não podem estar malpreparados, pois lidam com princípios muito caros para a humanidade, que foram conquistados com muita dificuldade e que formam a própria essência da pessoa, estando ligados ao Estado Democrático de Direito, à soberania e à segurança jurídica.

Ressalta-se também os outros desafios para a aplicabilidade prática do Direito Penal, que são as mudanças sociais atuais, posto que a sociedade moderna é caracterizada como "sociedade do risco", na qual quanto mais cresce a seletividade mais aumenta a complexidade.

Conclui-se que se faz necessário um currículo mais completo e complexo, que inclua na formação dos profissionais de Direito outras competências além do conhecimento do ordenamento jurídico vigente e suas técnicas processuais. Que a formação tenha a previsão do estudo da Criminologia, incluindo a Criminologia Crítica, do Direito Penal e de Política Criminal para os cursos de Direito. O ensino da Criminologia Crítica integrado ao Direito Penal possui caráter decisivo com relação à forma de aplicação e interpretação do controle jurídico penal.

Nos debates envolvendo a Criminologia Crítica destaca-se um erro em relação ao não reconhecimento da seletividade na prática penal como fato social. E embora seja apontada uma crise na Criminologia Crítica é necessário incluir essa disciplina na matriz curricular para que o ensino jurídico possa acompanhar os debates e dessa forma contribuir para o enfrentamento da seletividade e propor outras formas de aplicabilidade da justiça penal.

Dessa forma, será efetivada a transversalidade do conhecimento para uma maior emancipação do futuro operador do Direito e superação de um dogmatismo de maneira a contribuir para uma formação humanística e com consciência jurídica crítica e responsável, colocando em prática a previsão das Diretrizes Curriculares Nacionais atuais para os cursos de Direito (Resolução no 9/2004), do Conselho Nacional de Educação (CNE). 
E assim será possível a formação de um profissional do Direito que tenha um pensamento crítico, uma visão mais humana e contextualizada e com possibilidades de atuar no Judiciário, no Ministério Público, nas Defensorias, como autoridade policial, entre outras profissões da área jurídica, apresentando soluções diversas para o enfrentamento das questões vivenciadas na sociedade complexa atual.

\section{REFERÊNCIAS}

ANDRADE, Vera Regina Pereira de. Porque a criminologia (e qual criminologia) é importante no Ensino Jurídico? Revista Jurídica da Universidade do Sul, Santa Catarina: Unisul, ano III, n. 6 jan./jun. 2017. Disponível em: htpp//:www.portaldeperiodicos. unisul.br/index.php/. Acesso em: 23 maio 2018.

BARATTA, Alessandro. Criminologia crítica e crítica do direito penal. 2. ed. Rio de Janeiro: Freitas Bastos, 1999.

BARATTA, Alessandro. Criminologia e dogmática penal. Passado e futuro do modelo integral da ciência penal. In: Revista de Direito Penal, Rio de Janeiro: Forense, n. 31, jan./jul. 1981.

BECK, Ulrich. Sociedade de risco: rumo a uma outra modernidade. Trad. Sebastião Nascimento. São Paulo: Ed. 34; 2010. 368p. BITTAR, Eduardo Carlos B. Direito e ensino jurídico: legislação educacional. São Paulo: Atlas, 2001. p. 15-16.

BITENCOURT, Cezar Roberto. Tratado de Direito Penal 1 - parte geral. 12. ed. São Paulo: Saraiva, 2012.

BRASIL. Lei 9394, de 20 de dezembro de 1996. LDBN. Estabelece as Diretrizes e Bases da Educação Nacional. Diário Oficial da Republica Federativa do Brasil, Brasília, DF, n. 248, 23 dez. 1996.p. 27.833-27.841.

BRASIL. Conselho Nacional de Educação (CNE). Câmera de Ensino Superior (CES). Resolução CNE/CES no 9, de 29 de setembro de 2004. Diário Oficial da União, Brasília, DF, 1o out. 2004. Seção 1, p. 17.

CARVALHO, José Murilo de. A construção da ordem: a elite política imperial. Rio de Janeiro: Campus, 1980.

CARVALHO, José Murilo de. Cidadania no Brasil. O longo Caminho. 3. ed. Rio de Janeiro: Civilização Brasileira, 2002.

DE GIORGI, Raffaele de. Direito, democracia e risco - vínculos com o futuro. Porto Alegre: Sérgio Fabris Editor, 1998.

DE GIORGI, Raffaele de. Direito, tempo e memória. Tradução Guilherme Leite Gonçalves. São Paulo: Quartier Latin, 2006.

DE GIORGI, Raffaele de. The Risk of Risk Society and the Limits of Law. Sociologia del diritto, v. 2, 2009, p. 59-67.

ELIAS, Nobert. Os estabelecidos e os outsiders: sociologia das relações de poder a partir de uma pequena comunidade. Rio de Janeiro: Zahar, 2010.

FERREIRA, Carolina Costa. A criminologia crítica e suas crises: entre sujeitos, objetos, caminhos e outras definições. Revista Transgressões, v. 1, n. 1, p. 134-154, 28 jan. 2015. Disponível em: https://periodicos.ufrn.br/transgressoes/article/view/6601. Acesso em: 28 dez. 2019.

FILHO, Roberto Lyra. O Direito que se ensina errado: sobre a reforma do ensino jurídico. Brasília: Centro Acadêmico de Direito da UNB, 1980. FRANCISCHETTO, Gilsilene Passon P. Em busca de novos saberes: uma aproximação entre o ensino jurídico e a pedagogia. In: FRANCISCHETTO, Gilsilene Passon P. Ensino jurídico e pedagogia: em busca de novos saberes. Curitiba: Editora CRV, 2010.

FREIRE, Paulo. Pedagogia da autonomia: saberes necessários à prática educativa. 16 ed. São Paulo: Paz e Terra, 1996.

GRECO, Rogério. Código Penal: comentado. 5. ed. Niterói, RJ: Impetus, 2011.

LINHARES, Mónica Tereza Mansur. Ensino jurídico - educação, currículo e diretrizes curriculares no curso de Direito. São Paulo: Iglu, 2010. LUHMANN, Niklas. Sociología del riesgo. Traducción Silvia Pappe, Brunhilde Erker y Luis Felipe Segura. Coordinador de la traducción Javier Torres Nafarrate. México: Universidad Iberoamericana, 2006. (Colección Teoría Social).

MORIN, Edgar. Complexidade e transdisciplinaridade: a reforma da universidade e do Ensino Fundamental. Tradução Edgard de Assis Carvalho. Natal: EDUFRN, 2000.

MORIN, Edgar. Introdução ao pensamento complexo. Tradução Dulce Matos. Lisboa: Instituto Piaget, 2001.

MORIN, Edgar. Desafios da transdisciplinaridade e da complexidade. In: AUDY, Jorge Luis N.; MOROSINI, Marília Costa (org.). Inovação e interdisciplinaridade na universidade. Porto Alegre: EDIPUCRS, 2007.

PRANDO, Camila Cardoso de Mello; SANTOS, Rogerio Dultra dos. Porque estudar criminologia hoje? Apontamentos sobre um discurso contra-hegemônico à dogmática penal tradicional. 2016. Disponível em: https://emporiododireito.com.br/leitura/ porque-estudar-criminologia-hoje-apontamentos-sobre-um-discurso-contra-hegemonico-a-dogmatica-penal-tradicional. Acesso em: 28 dez. 2019.

PEDROTO, Fábio Almeida. Delegados de polícia da Grande Vitória e as políticas de drogas. Espírito Santo: Editora Milfontes, 2018. SOUZA SANTOS, Boaventura. A globalização e as Ciências Sociais. 2. ed. São Paulo: Cortez, 2002.

SIEBER, Ulrich. Limites do direito penal: princípios e desafios do novo programa de pesquisa em direito penal no Instituto Max-Planck de direito penal estrangeiro e internacional. Revista Direito GV, v. 4, n. 1, p. 269-330, jun. 2008. Disponível em: www.scielo.br/pdf/rdgv/v4n1/a12v4n1.pdf. Acesso em: 28 dez. 2019.

WOLKMER, Antonio Carlos. História do Direito no Brasil. 5. ed. Rio de Janeiro: Forense, 2000. 